\title{
A comparative study of dextran-70, warfarin and low-dose heparin for the prophylaxis of thrombo-embolism following total hip replacement
}

\author{
H. M. BARBER \\ F.R.C.S., F.R.C.S.E. \\ C. S. B. GallasKo
Ch.M., F.R.C.S. \\ R. A. SUtTon \\ F.R.C.S.E.
}

\author{
E. J. FEIL \\ M.D. \\ D. H. EDWARDS
F.R.C.S. \\ D. W. HAYNES \\ A.I.M.L.T.
}

G. BENTLEY
Ch.M., F.R.C.S.

Summary

In a randomized, controlled clinical study, dextran-70, warfarin, or low-dose heparin were administered to patients undergoing total hip replacement on one surgical unit in an attempt to prevent deep venous thrombosis and pulmonary embolism. Calf vein thrombosis was detected by the ${ }^{125}$ I-fibrinogen uptake test. None of the methods prevented calf vein thrombosis (dextran-70, 51\%; warfarin, 58.6\%; heparin, $52.6 \%$ ). Pulmonary embolism was completely prevented in patients treated with warfarin but occurred in $4 \%$ of patients treated with dextran-70 and $15.5 \%$ of those treated with low-dose heparin. The incidence of complications of therapy was small and comparable in each group. It is suggested that calf vein thrombosis is a frequent and in itself a non-serious complication of total hip replacement surgery and that emphasis might be placed more usefully on prevention of pulmonary embolism.

\section{Introduction}

Elective orthopaedic procedures such as total hip replacement performed on patients of advanced age pose a particular problem in management. There is a greater incidence of deep venous thrombosis (DVT) and pulmonary embolism (PE) in this than in any other group of surgical patients, with a DVT rate of $50-54 \%$ and pulmonary embolism rate of $4-12.5 \%$ (Evarts and Feil, 1971; Hampson et al., 1974; Morris, Henry and Preston, 1974). Many attempts have been made to avert the important complication of pulmonary embolism by preventing deep venous thrombosis in the calf, on the assumption that all thrombi originate in the calf veins and exten⿳亠丷厂巾 proximally before embolism occurs. Strong claims. have been made for the efficacy of low-dose hepapitipe (Kakkar et al., 1972; Morris et al., 1974) in prevest:ing calf thrombi, but other reports have not bēêt confirmatory (Hampson et al., 1974; Harris et $\overrightarrow{a t} t ?$ 1974). Dextran-40 (Evarts and Feil, 1971) anfึ dextran-70 (Bonnar and Walsh, 1972) have als\& reduced the incidence of calf thrombosis dramaticall $\mathbb{B}$ but total prevention has been achieved rarely Moreover, various authors have reported 'silent? pelvic vein thrombosis with subsequent pulmonary embolism in the absence of calf vein thrombosis in up to $50 \%$ of cases (Sevitt and Gallagher, 1959\% Mavor et al., 1972; Harris et al., 1974). The ora $\mathrm{B}$. anticoagulants phenindione (Sevitt and Gallagherio 1959) and warfarin (Harris, Salzman and de Sanctis ș. 1967; Harris et al., 1972; Muckle, Forney an Bentley, 1974) have been reported as preventing pulmonary embolism completely although bleeding complications have occurred in a small percentages of cases following hip surgery and dosage contro? has sometimes proved difficult (Muckle et al., 1974)

In view of the uncertainty of the efficacy of curren? methods of preventing deep venous thrombosis and pulmonary embolism a prospective, randomized controlled clinical trial was set up in one surgicab unit, in which techniques of pre-, per- and posto operative management were as standard as possible Previously, warfarin therapy had completely pre? vented pulmonary embolism following total hipo replacement in this unit (Muckle et al., 1974) Accordingly, a comparison of the effect of low dose 
heparin administered twice daily, dextran-70, and warfarin commencing $36 \mathrm{hr}$ after operation, on the whole pattern of deep venous thrombosis and pulmonary embolism was made. Dextran-70 was chosen in preference to dextran-40 because of its longer half-life in the circulation $(40 \%$ excretion in $24 \mathrm{hr}$ ) and presumed more uniform anticoagulant effect, and its reported efficacy in prophylaxis of deep venous thrombosis (Bonnar and Walsh, 1972). A control group was not considered justifiable in view of previous experience on this unit with warfarin and a review of the literature.

\section{Patients and methods}

Between February 1973 and October 1975 all patients admitted to the Nuffield Orthopaedic Centre for total hip replacement, under the care of one surgical team, were considered for inclusion in the trial. Those with the following conditions were excluded:

(1) Past history of malignancy, thrombo-embolism or peptic ulceration.

(2) Steroid or salicylate therapy. This excluded patients with rheumatoid arthritis.

All suitable patients were randomly allocated to a treatment group. On the day before surgery the patient was given $120 \mathrm{mg}$ potassium iodide orally; this dose was continued daily until the patient was discharged from hospital. All patients had a Charnley-type of total hip prosthesis implanted. Immediately after operation, $100 \mu \mathrm{Ci}$ of ${ }^{125} \mathrm{I}$-labelled fibrinogen (supplied by the Radiochemical Centre, Amersham) were administered intravenously. At the end of the operation the limb was placed on a Hodgen's splint and active contraction of all leg muscles was encouraged on recovery of consciousness. Thereafter, the patients spent $1 \mathrm{hr}$ each morning and afternoon performing active exercises under the supervision of a physiotherapist, with as much movement as possible at all times. After 10 days the splints were removed and sling exercises commenced in bed. Walking with crutches began 10-14 days after operation.

Independent scanning and clinical examination of the legs were performed daily until the patients were mobilizing freely with crutches, between 11 and 14 days postoperatively.

\section{Details of treatment}

(1) Dextran-70 was administered as $1000 \mathrm{ml}$ starting with induction of anaesthesia, $1000 \mathrm{ml}$ daily for 3 days and then $500 \mathrm{ml}$ on alternate days for 10 days. Blood urea and electrolyte levels were monitored daily during dextran therapy as a guide to renal function.

(2) Warfarin was begun $36 \mathrm{hr}$ after surgery; 15 mg loading dose was followed by none on the next day and $5 \mathrm{mg}$ on the day after that. Thereafter the dosage was adjusted to maintain a prothrombin time of $10-20 \%$ and continued for 3 weeks.

(3) Heparin, 5000 units, was given subcutaneously into the abdominal wall at $12 \mathrm{hr}$ intervals commencing on the evening before surgery, for 3 weeks.

The scanning technique was that described by Atkins and Hawkins (1965). Measurement was performed with a Ratemeter, Type R.M.5 (Nuclear Enterprises U.K.) at points $10 \mathrm{~cm}$ apart on the medial aspect of the leg beginning at the medial malleous. A change of $20 \%$ in the count between adjacent points, persisting for $48 \mathrm{hr}$, was considered diagnostic of deep venous thrombosis. Venograms were performed on patients with calf thrombosis who had clinical evidence of proximal propagation such as oedema or tenderness over the thigh vessels. Pulmonary embolism was confirmed by lung field scanning.

\section{Results}

Of the 128 patients included in the trial, seventyeight were female and fifty were male. Ages ranged from 39 to 85 years, with a mean of 65.5 years (Fig. 1).

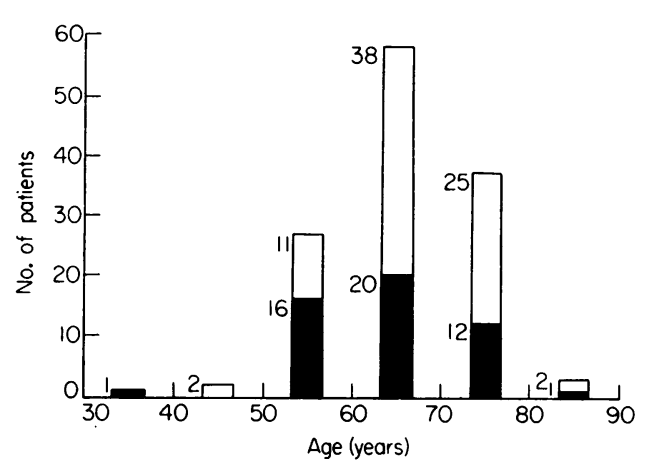

Fig. 1. Histogram to show age and sex distribution of patients. $\square$, female; $\square$, male.

\section{Deep vein thrombosis}

Deep venous thrombosis developed in seventy patients $(54 \cdot 7 \%)$. There was no significant difference in the incidence of deep venous thrombosis in the distal veins in those patients receiving dextran-70 compared with twice-daily subcutaneous heparin $\left(\chi^{2}=3.02\right.$; d.f. $\left.=1 ; 0.10>P>0.05\right)$, warfarin compared with heparin $\left(\chi^{2}=0.21 ;\right.$ d.f. $\left.=1 ; 1.0>P>0.10\right)$, or dextran-70 compared with warfarin $\left(\chi^{2}=0.64\right.$; d.f. $=1 ; 1.0>P>0.10$ ).

\section{Pulmonary embolism}

There were five episodes of pulmonary embolism overall. Three of these were in the first nineteen 
patients $(15 \cdot 8 \%)$ who received subcutaneous heparin and one was fatal. Post-mortem confirmed pulmonary embolism which was from thrombosis in the right femoral vein although scanning and clinical examination had shown no evidence of deep venous thrombosis, suggesting a pre-operative thrombus. At this point the heparin trial was discontinued. The other two emboli were in patients receiving dextran $(4 \%)$ and one of these was fatal. Neither patient had a calf thrombosis up to 14 days after operation.

\section{Results in the three treatment groups}

(1) Dextran (Table 1). Of fifty-one patients (eighteen male, thirty-three female) who received dextran-70, twenty-six had calf DVT $(51 \%)$.

TABLE 1. Dextran-incidence of deep vein thrombosis (DVT) and pulmonary embolism (PE)

\begin{tabular}{lrrrrrr}
\hline \multicolumn{1}{c}{ Sex } & \multicolumn{2}{c}{ Male } & \multicolumn{2}{c}{ Female } & & Total \\
\cline { 1 - 2 } \cline { 5 - 6 } Age (years) & $<70$ & $>70$ & $<70$ & $>70$ & \\
Patients & 14 & 4 & 25 & 8 & 51 \\
DVT & 4 & 2 & 15 & 5 & $26(51 \%)$ \\
No DVT & 10 & 2 & 10 & 3 & 25 \\
PE & 0 & 1 & 0 & 1 & $2(4 \%)$ \\
No PE & 14 & 3 & 25 & 7 & .49 \\
\hline
\end{tabular}

There was no significant difference at the $5 \%$ level between patients of 70 years and younger compared with those 71 years or older, or between the sexes at any age. Pulmonary embolism occurred in two patients $(4 \%)$ and was fatal in one of these. Whilst in hospital, there had been no evidence of DVT in either patient and the embolic episodes developed 31 and 38 days after operation. Thus the emboli almost certainly arose from 'silent' thrombi above the calf vessels.

(2) Warfarin (Table 2). Of fifty-eight patients who received warfarin (twenty-two male, thirty-six female), thirty-four $(58.6 \%)$ had DVT.

TABLE 2. Warfarin-incidence of deep vein thrombosis (DVT) and pulmonary embolism (PE)

\begin{tabular}{lrrrrl}
\hline \multicolumn{1}{c}{ Sex } & \multicolumn{2}{c}{ Male } & \multicolumn{2}{c}{ Female } & Total \\
\hline Age (years) & $<70$ & $>70$ & $<70$ & $>70$ & \\
Patients & 16 & 6 & 24 & 12 & 58 \\
DVT & 6 & 5 & 14 & 9 & $34(58 \%)$ \\
No DVT & 10 & 1 & 10 & 3 & 24 \\
PE & 0 & 0 & 0 & 0 & 0 \\
No PE & 16 & 6 & 24 & 12 & 58 \\
\hline
\end{tabular}

There was a significantly decreased incidence of DVT in those patients receiving warfarin aged 70 years or less compared with the older group ( $P=$ 0.047 ) but no significant difference occurred between the sexes in either group or in total. No pulmonary embolism was recorded in this group.
(3) Heparin (Table 3). Only nineteen patients received heparin (eight male, eleven female) and teg of these had DVT $(52.6 \%)$ before the group was discontinued.

TABLE 3. Heparin-incidence of deep vein thrombosis (DVT) and pulmonary embolism (PE)

\begin{tabular}{|c|c|c|c|c|c|}
\hline \multirow{2}{*}{$\frac{\text { Sex }}{\text { Age (years) }}$} & \multicolumn{2}{|c|}{ Male } & \multicolumn{2}{|c|}{ Female } & Total $\stackrel{\nabla}{\otimes}$ \\
\hline & $<70$ & $>70$ & $<70$ & $>70$ & D \\
\hline Patients & 6 & 2 & 6 & 5 & 19 \\
\hline DVT & 1 & 2 & 3 & 4 & $10(52 \%)$ \\
\hline No DVT & 5 & 0 & 3 & 1 & 9 \\
\hline $\mathrm{PE}$ & 1 & 0 & 1 & 1 & $3\left(15.8^{\circ}\right.$ \\
\hline No PE & 5 & 2 & 5 & 4 & 16 \\
\hline
\end{tabular}

Although the numbers were small there was significant lessening of DVT in the younger age group $(P=0.04)$ but no difference could be related tô sex.

Three patients on this regime developed pul monary embolism within 12 days of operation? one of these was fatal. The fatality occurred 8 days postoperatively with no clinical evidence of DVT ant a negative scan, suggesting a pre-operative throm $\bar{P}$ bosis. Thrombosis and embolism were diagnosed at post-mortem. The other two patients with pulmongry emboli had a positive calf vein scan. The embirit occurred at 1 and 12 days and were confirmed $\overline{\$}$ p pulmonary scanning.

\section{Complications of treatment}

Wound haematoma. Wound haematoma occurre in thirty patients $(23 \%)$. Fourteen had received warfarin; thirteen, dextran; three, heparin; onlÿ one haematoma was large enough to require surgicat evacuation and all healed satisfactorily. No bleeding. occurred from other sites.

Wound infection. There were no deep wound infections.

Complications of dextran-70 therapy. Four patients. developed complications with dextran-70 which necessitated cessation of the infusions. One developed an allergic reaction to dextran, one persistent bleeding at the drip site, one a raised blood urea and one congestive cardiac failure. Two으. others had their infusions stopped in error by the nursing staff. The dextran-70 infusions were resented ${ }^{\circ}$ by some of the patients since they interfered with 5 freedom of movement and they required close supervision by the nursing and medical staff.

\section{Discussion}

Deep vein thrombosis

The overall incidence of DVT in the distal veins 0 in this series $(54.7 \%)$ is considerably higher than the $32 \%$ untreated patients, and the $36 \%$ treated with 
warfarin, detected by Pinto (1970) using the radioisotope method, although his patients included some with hip fractures who have a lower incidence. The incidence approximates closely to the $53.6 \%$ of Evarts and Feil (1971), the $54 \%$ of Hampson et al. (1974) and $50 \%$ of Morris et al. (1974) occurring in untreated patients. The present authors conclude that either the incidence of deep venous thrombosis in untreated patients in this high-risk group is higher than $55 \%$ or the incidence of DVT in untreated patients is of the order of $55 \%$ and the methods used in this trial had no prophylactic effect. The reasons for this may be: (a) heparin was given only twice daily and this probably is insufficient. Individual response to heparin is very variable (Brozovic et al., 1974); (b) warfarin was not begun until $36 \mathrm{hr}$ after operation and the majority of calf thrombi have formed by this time (Hampson et al., 1974); (c) dextran-70 was administered according to a regime which is not prophylactic in terms of dose or timing.

A review of the literature shows that complete prevention of calf thrombi has never been achieved in this high-risk group of patients by any agent. Moreover, 'silent' thrombosis may occur in the proximal deep veins in the absence of thrombi in the calf veins. Therefore, the use of the absence of calf vein thrombosis as a criterion of the success of a regime to prevent thromboembolism is invalid in this group of patients.

\section{Pulmonary embolism}

The results show that pulmonary embolism was not prevented by heparin or dextran-70 where the incidence was $15.8 \%$ and $4 \%$ respectively. In the dextran group the onset of embolism was postponed until 31 and 38 days after operation, but embolism was within 12 days of surgery in the three cases receiving heparin. In the fifty-eight patients receiving warfarin no pulmonary embolism occurred. This accords with the findings of Harris et al. (1967, 1974) that no emboli occurred in patients receiving warfarin following hip replacement procedures.

Complications of therapy were no greater with warfarin than with heparin and dextran-70. The incidence of wound haematomata was not significantly different in the three groups. Haemorrhage from other sites did not occur in any group, and the wound sepsis rate was zero. Warfarin was subjectively reported by the patients, and by the medical and nursing staff, to be the easiest therapy to administer, although it involves the most laboratory effort, cost and time, and dextran-70 the most difficult.

On the basis of this investigation the authors recommend the use of warfarin as a safe method for the prophylaxis of pulmonary embolism, following total hip replacement, in preference to dextran-70 or twice-daily subcutaneous heparin. Its effects might be increased by commencing administration before operation as suggested by Harris et al. (1974).

\section{Acknowledgments}

We wish to thank Professor R. B. Duthie, on whose unit this trial was conducted, for guidance throughout. Also the nursing staff who facilitated the study by their enthusiasm. The prothrombin estimations were performed in the Haematology Department of the Churchill Hospital, Oxford. Dr A. Barr, M.Sc.(Econ), Ph.D. kindly carried out the statistical evaluation. The manuscript was typed by Mrs J. M. Lever.

\section{References}

Atkins, P.D. \& Hatvkins, L.A. (1965) Detection of venous thrombosis in the legs. Lancet, ii, 1217.

Bonnar, J. \& Walsh, J. (1972) Prevention of thrombosis after pelvic surgery by British Dextran-70. Lancet, i, 614.

Brozovic, M., Stirling, Y., Klenerman, L. \& Lowe, L. (1974) Subcutaneous heparin and postoperative thromboembolism. Lancet, ii, 99.

Evarts, C.M. \& FeIL, E.J. (1971) Prevention of thromboembolic disease after elective surgery of the hip. Journal of Bone and Joint Surgery, 53A, 1271.

Hampson, W.E.J., Harris, F.C., Lucas, H.K., Roberts, P.H., McCall, I.W., Jackson, P.C., Powell, N.L. \& Staddon, G.E. (1974) Failure of low dose heparin to prevent deep-vein thrombosis after hip replacement arthroplasty. Lancet, ii, 795.

Harris, W.H., Salzman, E.W., Athanasoulis, C., Waltman, A.C., Baum, S. \& DE SANCTIS, R.W. (1974) Comparison of warfarin, low molecular-weight dextran, aspirin and subcutaneous heparin in prevention of venous thrombo-embolism following total hip replacement. Journal of Bone and Joint Surgery, 56A, 1552.

Harris, W.H., Salzman, E.W. \& De Sanctis, R.W. (1967) The prevention of thromboembolic disease by prophylactic anticoagulation. Journal of Bone and Joint Surgery, 49A, 81.

Harris, W.H., Salzman, E.W., de Sanctis, R.W. \& Coutts, R.D. (1972) Prevention of venous thromboembolism following total hip replacement. Journal of the American Medical Association, 220, 1319.

KakKar, V.V., Corrigan, T., SPindler, J., Fossard, D.P., Flute, P.T., Crellin, R.W., Wessler, S. \& Yin, E.T. (1972) Efficacy of low doses of heparin in prevention of deep venous thrombosis after major surgery. Lancet, ii, 101.

Mavor, G.E., Mahaffy, R.G., Walker, M.G., Duthie, J.S., Dhall, D.P., Gaddie, J. \& ReID, G.F. (1972) Peripheral venous scanning with ${ }^{125}$ I-tagged fibrinogen. Lancet, i, 661.

Morris, G.K., Henry, A.P.J. \& Preston, B.J. (1974) Prevention of deep-vein thrombosis by low dose heparin in patients undergoing total hip replacement. Lancet, ii, 797.

Muckle, D.S., Forney, H.J. \& Bentley, G. (1974) The value of prophylactic anticoagulant therapy with warfarin after hip surgery. Acta orthopaedica scandinavica, 45, 412.

PINTO, D.J. (1970) Controlled trial of an anticoagulant (warfarin sodium) in the prevention of venous thrombosis following hip surgery. British Journal of Surgery, 57, 349.

Sevitt, S. \& Gallagher, N.G. (1959) Prevention of venous thrombosis and pulmonary embolism in injured patients. Lancet, ii, 981. 